\title{
Specialist work schemes: user satisfaction and costs
}

\author{
Justine Schneider and Angela Hallam
}

\begin{abstract}
This paper is a study of the costs and quality of life of 157 people attending specialist employment schemes for people with long-term mental health problems in southeast England. The research, work force, and the seven work seltings are described and offierences found between service users in satisfaction, social networks and costs of 1994-95 lovels are reported. This is the first such study of work schemes in this country, and while still not generallsable, It supplles valuable empirical evidence for all those concemed with psychiatic rehabilltation.
\end{abstract}

Employment and occupational therapy have long been part of psychiatric treatment. Today, although most people receive mental health care outside hospital, there is still a growing demand for constructive occupation on the part of consumers and voluntary organisations which represent their views. Although the drive towards evidence-based health highlights the need for greater knowledge about the specific contribution of employment to psychiatric rehabilitation, few data are available. Developments in psychiatric day care, including the importation of US models such as the Clubhouse (Beard et al, 1982) and Supported Employment (Anthony \& Blanch, 1987) may be undertaken more judiciously if we understand the costs and benefits of the status quo. Sheltered or specialist work schemes are probably the most common form of employment opportunity in Britain for people disabled through mental health problems.

The research reported here is a preliminary attempt to describe a range of specialist work schemes, and to lllustrate some of the variations found in different schemes. This study provides baseline information about seven typical schemes, focusing particularly on those suitable for people with the most intractable mental health problems. In addition, we aimed to look at the social networks of the work force, to analyse and cost the service packages received by the workers, and to compare the cost of work schemes with a sample of day centres.

\section{The study}

We recruited seven schemes typical of those catering for people with long-term mental health problems, including three 'mixed' schemes with a range of activities, a vocational rehabilitation scheme, a Clubhouse-type scheme and two which resemble industrial therapy units. Three schemes offered full-time work, while the rest offered sessional work, with a few people working full-time. The Clubhouse scheme differed somewhat; a distinction may be made between people attending the Clubhouse as members and doing tasks associated with the running of the club, and people going off the premises on a work ('transitional employment') placement. Six of the 20 Clubhouse members interviewed were on work placements.

We interviewed 137 members of the established workforce and 20 newcomers, following up 15 of these people 9-12 months later. We assessed quality of life using the Lancashire Quality of Life Profile (LQOLP; Oliver et al, 1995), and costed all the services recently used by our subjects. We found some significant variations in life satisfaction, social networks, service use and costs.

\section{Results}

The established work force of service users had a mean age of $44 ; 69 \%$ of them were male and $82 \%$ were judged by scheme managers to need occupation because of deficits in social interaction. There was a wide range of functional impairment, $44 \%$ of subjects were taking antipsychotic medication, and $29 \%$ had been hospitalised before the age of 21 . Few people interviewed had academic or vocational qualifications. About a third were living in supported accommodation, a third with members of their family and a third were living alone. Workers on average put in 25 hours per week for a wage which ranged from $\$ 0.48$ to $£ 1.38$ per hour; their average weekly income including benefits was $£ 82$. just $25 \%$ of the average net male wage of £236 (Central Statistical Office, 1995). 
Work schemes

The differences in financial make-up between schemes are reflected in the net unit cost per hour (range £1.41-£6.96). The ratio of income to expenditure in the seven schemes ranged from 4-51\%, so no scheme broke even financially. The ratio of salaried staff to workers ranged from $0.13-0.33$.

\section{Satisfaction of service users}

At the individual level, all life satisfaction scores, except satisfaction with religion, were intercorrelated (a common finding with the LQOLP). Satisfaction with income had the lowest score of all. Some significant differences suggest hypotheses to be tested on more representative samples. For instance, people in the scheme with the shortest working week were less satisfied with their friends than those in four other settings, and people in the most urban setting were less satisfied with personal safety than those in a scheme where $75 \%$ lived in supported accommodation.

If we include Clubhouse tasks as work, satisfaction with employment in this scheme was significantly higher than in two of the other schemes $(P<0.05$, Student-Newman-Keuls $)$. However, if the comparison is restricted to Clubhouse members on work placements, there were no significant differences in work satisfaction between any of our study schemes. When members not working outside Clubhouse were considered separately, they were more satisfied with their activities (termed, for our purposes, 'work') than people in one of the other schemes. It appears, therefore, that the less formal structure of the Clubhouse may be associated with greater levels of satisfaction with daytime activity.

\section{Social networks}

On our measure, the size of personal social networks did not vary significantly between work schemes. In one setting, where there was a high proportion of former hospital residents, people had contact with fewer relatives.

We looked at reciprocal relationships, by asking "who depends on you?": people living in supported housing were significantly less likely to name anyone in response to this question. We found that independence from paid carers, and participation in reciprocal relationships, were positively associated with work satisfaction, while having a close friend was positively associated with general life satisfaction.
Service use and costs

Accommodation costs were significantly higher in the most central city setting, presumably reflecting market values of property. People living in supported accommodation used less health care and more social work, while their work scheme and (not surprisingly) housing costs were higher. Work schemes cost less for people taking antipsychotic drugs, but housing cost more, implying that they lived in supported accommodation. People in the vocational rehabilitation setting used significantly more education services than any other scheme and more psychiatry than most. In this setting there was a psychiatrist on the premises, which seems to have had an impact on use of this service. Compared with their younger colleagues, workers over 50 cost less in terms of health care, mental health services, day care and 'other' services, but their costs for work schemes and accommodation were greater.

Comparisons with day care for the same user group

A number of people in our study were using day centres run by the NHS, local authorities or voluntary providers. We costed these, using the same methods by which we had costed the work schemes (Schneider, 1996). Mean work scheme costs per week were higher than any of the day care averages. However, one of the entry criteria to our study was attendance for at least two sessions (one day) per week; also, as mentioned elsewhere, full-time attendance was mandatory in three of the schemes. When we standardised for attendance, we found that the mean unit cost per day of the work schemes in our study (£17.48) was less than that for the day care alternatives which the same people were using (£25.59-£81.53).

\section{Conclusions}

The work of Dick \& Shepherd (1994) and Nehring et al (1993) represents most of the contemporary published data about work schemes in Britain. While the data presented here are also crosssectional and pertain to an opportunistic sample of work schemes, they go some way towards adding to our knowledge about specialist work schemes in England. Here we have demonstrated some useful measures for evaluating work schemes or similar forms of intervention, and further information may be gathered by applying our methodology elsewhere. We hope to have begun to unpack the 'black box' of specialist employment provision, and point the way towards further research. 


\section{Acknowledgement}

We thank the Department of Health for funding this study during 1995-96, our colleagues at the PSSRU, and the participants in this study.

\section{References}

ANTHONY, W. A. \& BLANCH, A. (1987) Supported employment for persons who are psychiatrically disabled: An historical and conceptual perspective. Psychosocial Rehabilitation Journal, 17, 3-13.

Beard, J. H., PRobst, R. M. \& Malamud, T. J. (1982) The Fountain House model of psychiatric rehabilitation. Psychosocial Rehabilitation Journal, 5, 47-53.

Central Statistical Office (1995) Social Trends 1996. CSO. London: HMSO.

DICK, N. \& SHEPHERD, G. (1994) Work and mental health: A preliminary test of Warr's model in sheltered workshops for the mentally ill. In Vocational Rehabilitation Research in Mental Health (eds Zeelen. Seygried \& van Weighel), pp. 59-76. Utrecht: Lemma.
NEHRING, J., Hill, R. \& POOLE, L. (1993) Work Empowerment and Community. Research and Development for Psychiatry, London.

OLIVER, J., HuXIEY, P., BRIDGES, K., et al (1995) Quality of Life and Mental Health Services. London: Routledge.

SCHNEIDER, J. (1996) Costing specialist work schemes. In Unit Costs of Health and Social Care, 1996 (eds A. Netten \& J. Dennet), pp. 28-31. University of Kent at Canterbury: Personal Social Services Research Unit.

*Justine Schneider, Research Fellow; and Angela Hallam, Research Fellow, Personal Social Services Research Unit, University of Kent at Canterbury CT2 7EF; email: J.Schneider@ukc.ac.uk

*Correspondence

\section{Recent Council Reports}

CR47 College policy statement on rape, $£ 7.50$

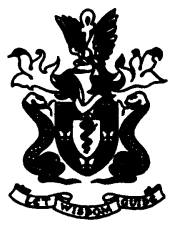

CR48 Report of the Working Party to review psychiatric practices and training in a multi-ethnic society, $£ 5.00$

CR49 Consensus statement on the assessment and investigation of an elderly person with suspected cognitive impairment by a specialist old age psychiatry service, $£ 5.50$

CR50 'Wish you were here'? Ethical considerations in the admission of patients to substandard psychiatric units, $£ 2.50$

CR51 The Responsiblities of Consultant Psychiatrists, $£ 5.00$

CR52 Sexual Abuse and Harassment in Psychiatric Settings, $£ 5.00$

CR53 Assessment and clinical management of risk of harm to other people, $£ 3.00$

CR54 Chronic fatigue syndrome, $£ 10.00$

Available from the Publications Department, Royal College of Psychiatrists, 17 Belgrave Square,

London SW1X 8PG (Tel. +44(0)171 235 2351, extension 146). The latest information on College publications is available on the INTERNET at: http://www.demon.co.uk/rcpsych/ 